\title{
A database of water and heat observations over grassland in the north-east of Japan
}

\author{
Wenchao Ma ${ }^{1}$, Jun Asanuma ${ }^{1,2}$, Jianqing $\mathrm{Xu}^{3}$, and Yuichi Onda ${ }^{1,2}$ \\ ${ }^{1}$ Center for Research in Isotopes and Environmental Dynamics, University of Tsukuba, \\ Tsukuba, 305-8577, Japan \\ ${ }^{2}$ Faculty of Life and Environmental Sciences, University of Tsukuba, Tsukuba, 305-8577, Japan \\ ${ }^{3}$ College of Business Administration, Kanto Gakuin University, Yokohama, 236-0037, Japan \\ Correspondence: Wenchao Ma (wma@ied.tsukuba.ac.jp) \\ Received: 23 April 2018 - Discussion started: 6 August 2018 \\ Revised: 22 October 2018 - Accepted: 29 October 2018 - Published: 18 December 2018
}

\begin{abstract}
A highly valuable database of long-term hydrometeorological measurements is presented, containing in situ observations for a period of 37 years from a well-maintained grassland in the north-east of Japan. The observations include shortwave radiation, net radiation, air and dew point temperatures at three elevations, soil temperature at four depths, sensible heat flux, soil heat flux, wind speed, relative humidity, air pressure and precipitation. The heights of measurements are 1.6, 12.5 and $29.5 \mathrm{~m}$ above ground, with the soil-layer observations at depths of $0.02,0.1,0.5$ and $1 \mathrm{~m}$. This high-quality database includes four temporal resolutions of $10 \mathrm{~s}, 0.5 \mathrm{~h}$, $1 \mathrm{~h}$ and $24 \mathrm{~h}$, with the hourly data presented here. Monthly and annual statistics are presented at the database web page of the Center for Research in Isotopes and Environmental Dynamics and Prediction of the University of Tsukuba, http://doi.org/10.24575/0001.198108. We validated the data by comparing them with published data from the local meteorological agency in Tateno operated by the Japan Metrological Agency, including the average, maximum and minimum values of air temperature, shortwave radiation, wind speed, relative humidity and precipitation. We have generated a daily downward longwave radiation time series with a method developed by Kondo and Xu (1997) based on the observations from the database. This constructed time series agrees well with observations collected between 2002 and 2006, as evaluated based on the values of the Nash-Sutcliffe efficiency $(=0.947)$ and percent bias $(=1.486)$. For the whole database, annually averaged values show a positive trend in precipitation, air temperature, shortwave radiation, net radiation and sensible heat flux over the past 37 years, with a negative trend detected for wind speed, soil heat flux and soil temperature.
\end{abstract}

\section{Introduction}

In situ observational databases play a dominant role in all research disciplines. In hydrometeorological studies, water and temperature observations from field work are essential for validating differently sourced data (Jackson et al., 2009; Liang et al., 2011; Guillevic et al., 2012), supporting theoretical modeling (Grayson and Blöschl, 2001), estimating the energy budget (Hirschi and Seneviratne, 2017; Makarieva et al., 2018) and recording historical climatic variation (Godsey et al., 2018; Kormos et al., 2018) for different subjects (Qu et al., 2016; Godsey et al., 2018). A full set of in situ hydrometeorological observations is introduced here from a well-maintained grassland located in the north-east of Japan, which has been continuously operated since 1981 by the Environmental Dynamics \& Prediction (EDP) department of the Center for Research in Isotopes and Environmental Dynamics of the University of Tsukuba, Japan. This observational site has a long history of providing important contributions to multidisciplinary investigations in many aspects of geological, hydrological, biological and meteorological studies, including micrometeorology both within and outside of the plant community as well as investigations into the transportation of turbulence, evapotranspiration, the soil energy budget and groundwater movement (Kawamura, 1991). 
For decades, the EDP department has provided a highquality database for many valuable studies assessing the energy balance and the degree of evapotranspiration. For example, Nakagawa (1983) tested the possibility for estimating actual evapotranspiration using an equilibrium evaporation model. Sugita et al. (1985) developed an apparatus for measuring the heat pulse velocity for estimation of the transpiration flux by employing the energy-budget method, while investigating the effect of stemflow and vegetation storage on the evapotranspiration. Sugita and Kotoda (1985) tested the effects of the soil-water deficits on forest evapotranspiration based on the observations from the EDP database, from which the effective rate of soil-moisture consumption was estimated and shown to be more than half the amount controlling the suppression of the evapotranspiration. In that same year, another advanced technology was employed (Sugita and Kotoda, 1985), which combined using the remotely sensed, land-surface temperature as well as Priestley-Taylor-type equations, for estimating the regional evapotranspiration. By evaluating the observations in 2001, Yubasaki et al. (2005) tested whether a reduction factor for pasture can be used for the turf site by comparing the evapotranspiration estimated by Penman, energy-budget eddy covariance and energy-balance Bowen ratio methods. Saito and Yamanaka (2005) carried out a quality control of the data and analyzed the evapotranspiration data observed with a weighing lysimeter between 1981 and 2002, with the results of the data quality summarized. In 1983, a model was developed by Tase and Majima (1983) for estimating precipitation under the influence of interception. This model showed good adaptability with the canopy, stem and evapotranspiration components. In addition, latent heat flux was assessed by Hiyama et al. (1993), with flux behavior compared before and after the precipitation event as well as an investigation into temporal variation and an assessment of measurement accuracy.

Investigations into the water and energy transfer, not only above ground, but also within the soil layers, have also been extensively carried out. For example, Sakura (1979) tested the infiltration effect for soil-water movement and soil temperature. Taniguchi (1990) specified the distribution of heat transport within soil layers by using observations of soil temperature. Sakura and Taniguchi (1983) conducted experiments at the EDP site to test the characteristics of soil-water movement during infiltration. Measurement errors were investigated by Iwata and Sugita (2006), who demonstrated the reliability of the observed heat fluxes.

A variety of studies on ecology and vegetation were conducted because of the unique land surface covered by grassland. For example, Kotada and Hayashi (1980) investigated the micrometeorology of the vegetation, with specifying empirical parameters describing the vegetation growth state based on physical modeling. While Nasuno et al. (1989) estimated the turbulent fluxes with the eddy-covariance method to investigate the effect of forest and vegetation on the exchange of energy and water vapor. Another study was car- ried out by Hayashi et al. (1989) to investigate the water vapor and temperature profile on this grassland. Being a wellmaintained observation site, the grassland provides good conditions for fundamental ecological research. For example, Yasui and Oikawa (1993) investigated the $\mathrm{CO}_{2}$ flux resulting from soil respiration, showing a high correlation between the soil temperature, moisture and respiration. Based on the unique land-surface characters, Yamanaka et al. (2005) conducted experiments to investigate the biomass and root characteristics at the site.

As a newly developed and reliable approach, the isotope method has also been applied extensively in the investigations of the water and temperature observations within the EDP database. Generally, branches of isotopic research in hydrological applications include the fields of hydrometeorology, eco-hydrology, groundwater hydrology, watershed hydrology and the use of isoscapes (Yamanaka, 2012), with isotopic techniques being well accepted as a powerful and stable method for partitioning the transpiration from the evapotranspiration. In particular, Shimizu and Yamanaka (2005) tested the spatial structure of the isotopic composition of the atmospheric water vapor at the micrometeorological scale over this observational site and analyzed the mixing processes of water vapor with different sources. Wang and Yamanaka (2014) developed a new method based on a twosource model for the growing season and demonstrated the behavior of vegetation affected by physiological responses. Since then, numerical models of isotopic tracers have been developed (Wang et al., 2015), from which the Iso-SPAC model has evolved, with a steady-state assumption for the transpiration flux successfully reproducing seasonal variations of all the components of the surface-energy balance.

In recent decades, more attention has been paid to climate change, with the need for more comprehensive and diverse data sources. The advantage of a single-site database is the ability to provide refined, high-quality data, since a largescale database can easily overlook specific procedures occurring within certain events involving both water and energy transport. The purpose of this paper is to present the available data and the processes involved in their collection for providing high-quality observations over multiple frequency scales for assisting climate studies and energy-balance estimations in multiple ways, such as (1) providing a complete data set for water and temperature observations for modeling studies or theoretical investigations; (2) helping to compare forecasted and estimated values of the climate trend; (3) showing a unique data set representing the meteorological and hydrological variations located in the north-east of Japan; (4) providing a valuable and unique database for biological and ecological studies in a long-term, continually well-maintained grassland. 
(a)
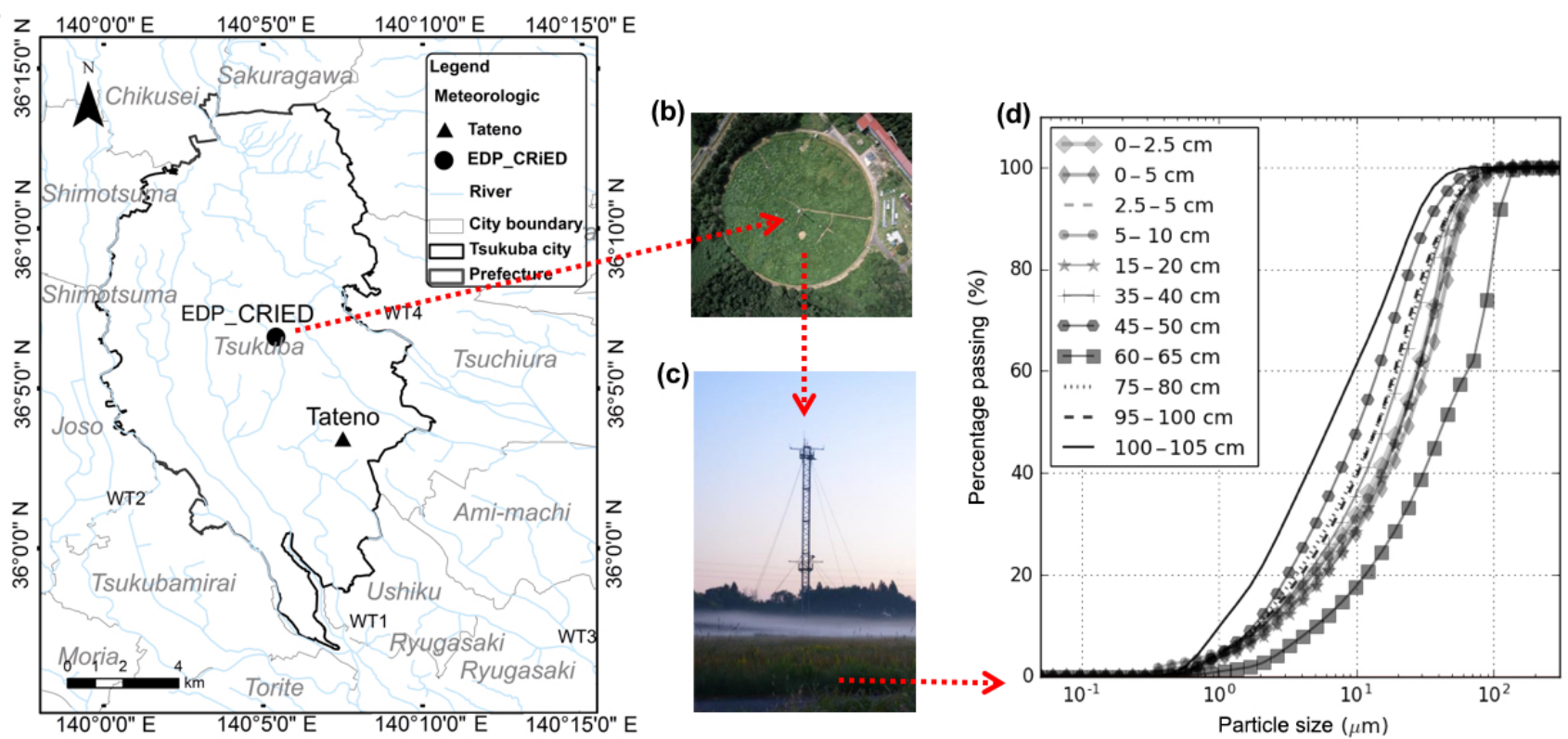

Figure 1. EDP observational site: (a) location, (b) projected view of the EDP grassland, (c) the observation tower and (d) results of the soil content analysis.

\section{Data description}

\subsection{Observational site, data and instrumentation}

The data were collected from an observational site located at the department of Environmental Dynamics and Prediction at the Center for Research in Isotopes $\left(36^{\circ} 06^{\prime} 35^{\prime \prime} \mathrm{N}\right.$, $\left.140^{\circ} 06^{\prime} 00^{\prime \prime} \mathrm{E}\right)$ in the grounds of the University of Tsukuba (Fig. 1a). This region has a semihumid marine climate with a long-term-average annual precipitation of 1200-1600 mm (Hamada et al., 1998). The observational site consists of a grass-covered circular field that is $160 \mathrm{~m}$ in diameter at an altitude of $27 \mathrm{~m}$ above sea level (a.s.1.), a meteorological observation tower at a height of $30 \mathrm{~m}$ equipped with sensors at heights of $1.6,10$ and $29.5 \mathrm{~m}$, and underground sensors at depths of $0.02,0.1,0.5$ and $1 \mathrm{~m}$, which monitor the soil temperature and heat flux (Fig. 1b and Table 1). All observed time series have been aggregated at frequencies of $30 \mathrm{~min}$, $1 \mathrm{~h}$ and $24 \mathrm{~h}$ since 1981 and at a frequency of $10 \mathrm{~s}$ since 2003. Being a continuous, long-term observational site, the maintenance and modernization of instrumentation has taken place to ensure high-quality observations, with the date on which each instrument was introduced found in Table 1.

The observational site was artificially filled with loam and volcanic ash soil in the top of $1 \sim 2 \mathrm{~m}$ and a clay layer with thickness of $4 \sim 5 \mathrm{~m}$, underneath (Sakura, 1977). Each soil layer consists of brown to dark sand, clay and loam in different ratios. A soil-particle-size analysis was carried out using a Shimadsu SALD-3100 particle analyzer, with the results shown in Fig. 1d. During the growing season, the lowest soil layer encounters groundwater at a depth of around $2 \mathrm{~m}$. The observational site is covered by multiple species of vegetation, with a similar percentage of species each year since 1977 (Imasu et al., 2002) providing consistent meteorological and hydrological research conditions throughout this period.

The vegetation is naturally grown $\mathrm{C}_{3}$ and $\mathrm{C}_{4}$ vegetation, such as Imperata cylindrica, Andropogon virginicus, Miscanthus sinensis as $\mathrm{C}_{4}$ and Solidago altissima, Artemisia princeps, Lespedeza cuneata, Lespedeza pilosa, Equisetum arvense, Festuca arundinacea, Potentilla freyniana, Lysimachia clethroides as $\mathrm{C}_{3}$. The similarities in grass species, depth and leaf-area index (LAI) were confirmed annually by two different surveys. Tanaka and Oikawa (1998) conducted a survey of the seasonal dynamics of the LAI for both $\mathrm{C}_{3}$ and $\mathrm{C}_{4}$ vegetation types, with results showing that the percentage of the species and the height of the vegetation had not changed dramatically since 1977 . Another survey was carried out between 2000 and 2002 to directly measure the LAI and height, with similar results found as before, such as the value of the LAI, which ranged from less than 0.1 in winter to nearly 5 during September, while the height of the grass is about $1 \mathrm{~cm}$ during winter and around $1.8 \mathrm{~m}$ in September and October (Imasu et al., 2002). Since 2006, the grass has been mown twice each year (summer and winter); dead plants and grass clippings were redistributed.

Most observations we present were observed directly, except for the dew point temperature $T_{\mathrm{d}}$, which, according to the historical record, has been collected by different instrumentation. While the initial instrumentation for the dew point temperature was a lithium chloride dew point thermometer, since 15 December 2006 this has been changed to a hygrom- 
Table 1. Instrumentation information of the EDP observational system.

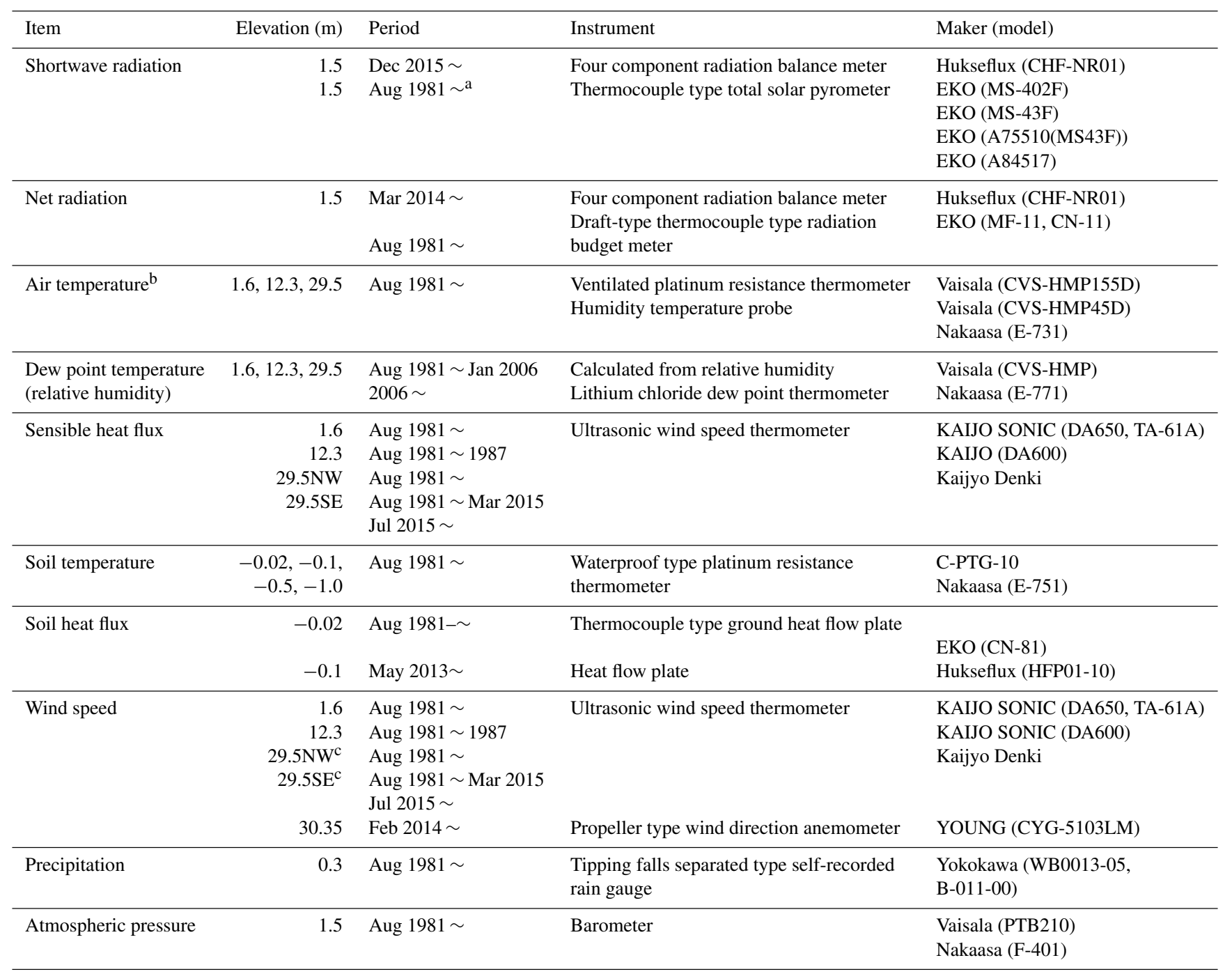

${ }^{\mathrm{a}}$ Frequency for all observation periods: $0.5,1$ and $24 \mathrm{~h}$. A frequency of $10 \mathrm{~s}$ was used starting in $2003 .{ }^{\mathrm{b}}$ Air temperature observations included average, maximum and minimum values. ${ }^{\mathrm{c}} \mathrm{NW}$ is northwest; SE is southeast.

eter (CVS-HMMP45D, Climatec), with the value of the dew point temperature calculated from the observed specific humidity by Watarai and Yamanaka (2007).

$T_{\mathrm{d}}=\frac{b \times \log _{10}\left(\frac{e}{6.11}\right)}{a-\log _{10}\left(\frac{e}{6.11}\right)}$,

$e=e_{\mathrm{sat}} \times \frac{\mathrm{RH}}{100}$,

where $a=7.5, b=237.3$, RH is the relative humidity expressed as a percentage, and the saturated vapor pressure $e_{\text {sat }}$ is obtained from

$e_{\mathrm{sat}}=6.11 \times 10^{\left(\frac{a T}{b+T}\right)}$,

where the temperature $T$ is given in ${ }^{\circ} \mathrm{C}$. Data collected from supersonic anemometer-thermometers were used to ob- tain heat and momentum fluxes using the eddy-correlation method. The data are freely available to download from the Center for Research in Isotopes and Environment Dynamics (CRiED) website (http://www.ied.tsukuba.ac.jp/en/ edps/database-doi/, last access: 22 October 2018) (formerly known as TERC) as hourly, monthly and annual summaries. Since 2003 the temporal resolution has been at 10 s, $30 \mathrm{~min}$, $60 \mathrm{~min}$ and $24 \mathrm{~h}$ intervals.

When calculating averaged data (Asanuma et al., 2004) at least 24 records at $30 \mathrm{~min}$ were required. Readings with less than 20 records were discarded (marked with "****" in the supplement data file) and data with between 20 and 24 records were annotated as incomplete (Ohba and Yamanaka, 2008; marked with "** in the supplement data file). In addition to the missing data, the dates of equipment maintenance, construction and mowing information are recorded in 
the maintenance log (http://www.ied.tsukuba.ac.jp/yosoku/ kansoku/hojyo_log/, last access: 22 October 2018).

\subsection{Estimation of downward longwave radiation}

Using a method developed by Kondo and $\mathrm{Xu}$ (1997), the downward longwave radiation flux is estimated from the routine meteorological observations, including the solar radiation, air temperature, relative humidity, air pressure, wind speed and precipitation (see Table 1 for instrumentation information), with the temporal resolution of the calculation chosen based on both the observed forcing data and the estimated downward longwave radiation. This method was successfully applied to the Tibetan Plateau ( $\mathrm{Xu}$ and Haginoya, 2001; Xu et al., 2005). In this study, the results of the estimation have been validated against the downward longwave radiation as directly observed by the EDP department between 2002 and 2007. To assess the model performance, the coefficient of determination $\left(R^{2}\right)$, Nash-Sutcliffe efficiency (NSE) and the percent bias (PBIAS) are considered.

\subsubsection{Estimation of downward longwave radiation}

The downward longwave radiation at the ground is estimated following Kondo et al. (1994) as

$L^{\downarrow}=\sigma T^{4}\left[1-\left(1-\frac{L_{\mathrm{f}}^{\downarrow}}{\sigma T^{4}}\right) C\right]$

$L_{\mathrm{f}}^{\downarrow}=\left(0.74+0.19 x+0.07 x^{2}\right) \sigma T^{4}$,

$x \equiv \log _{10} w^{*}$,

where $L^{\downarrow}$ is the downward longwave radiation for a cloudy day, $L_{\mathrm{f}}^{\downarrow}$ is the downward longwave radiation for a fine day, $T$ $(\mathrm{K})$ is the $1 \mathrm{~h}$ air temperature, $\sigma=5.670 \times 10^{-8} \mathrm{~W} \mathrm{~m}^{-2} \mathrm{~K}^{-4}$ is the Stefan-Boltzmann constant, and $w^{*}$ is the effective precipitable water expressed as

$w^{*}=\frac{1}{g} \int_{0}^{P_{\mathrm{s}}} q \frac{p}{p_{0}} \mathrm{~d} p$.

Here, $p_{0}=1013 \mathrm{hPa}$ is the standard atmospheric pressure, and $p_{\mathrm{s}}$ is the surface pressure $(\mathrm{hPa})$. The precipitable water $(\mathrm{cm})$ is estimated as

$\log _{10} w \approx \log _{10} w^{*}+0.10$,

and $C$ is the coefficient expressing the effect of clouds by

$$
\begin{aligned}
C & =0.03 B^{3}-0.03 B^{2}+1.25 B-0.04, \quad B \geq 0.0323 \\
& =0, \quad B<0.0323,
\end{aligned}
$$

where $B \equiv S_{\text {obs }}^{\downarrow} / S_{\text {top }}^{\downarrow}$, Here, $S_{\text {obs }}^{\downarrow}$ is the observed solar radiation flux, $S_{\text {top }}^{\downarrow}$ is the mean downward solar radiation at the top of the atmosphere,

$S_{\text {top }}^{\downarrow}=\frac{S_{00}}{\pi} d(\zeta \sin \phi \sin \delta+\cos \phi \cos \delta \sin \zeta)$, where

$$
\begin{aligned}
\zeta= & \cos ^{-1}\left(\frac{\sin \alpha-\sin \phi \sin \delta}{\cos \phi \cos \delta}\right), \\
d= & 1.00011+0.034221 \cos \eta+0.00128 \sin \eta \\
& +0.000719 \cos 2 \eta+0.000077 \sin 2 \eta, \\
\delta & =\sin ^{-1}[0.398 \times \sin (4.871+\eta+0.033 \sin \eta)], \\
\eta & =\frac{2 \pi}{365} \text { Day, }
\end{aligned}
$$

$S_{00}$ is the solar constant, $\zeta$ is the half-day angle, $\phi$ is the latitude, $\delta$ is the solar declination, and Day is the total number of days from 1 January to the day of observation. According to Kondo et al. (1994), the estimated downward longwave radiation is accurate to within $\pm 10 \mathrm{~W} \mathrm{~m}^{-2}$, with differences resulting from the effects of snow in winter.

\subsubsection{Model evaluation}

Evaluating the agreement between observed and simulated data is a basic requirement for the data quality control (Moriasi et al., 2007; Singh et al., 2005) for which the following indices are chosen: the coefficient of determination $\left(R^{2}\right)$ for describing the ratio of variance in the observations, the NashSutcliffe efficiency (NSE) for indicating the error in the units of the constituent between observed and simulated data, and the percentage bias (PBIAS) for measuring the average tendency of the simulated data to be larger or smaller than the corresponding observed data (Gupta et al., 1999). Here,

$$
\begin{aligned}
& \mathrm{NSE}=1-\left[\frac{\sum_{i=1}^{n}\left(Y_{i}^{\mathrm{obs}}-Y_{i}^{\mathrm{sim}}\right)^{2}}{\sum_{i=1}^{n}\left(Y_{i}^{\mathrm{obs}}-Y^{\mathrm{mean}}\right)^{2}}\right] \\
& \mathrm{PBIAS}=\left[\frac{\sum_{i=1}^{n}\left(Y_{i}^{\mathrm{obs}}-Y_{i}^{\mathrm{sim}}\right) \cdot(100)}{\sum_{i=1}^{n}\left(Y_{i}^{\mathrm{obs}}\right)}\right],
\end{aligned}
$$

where $n$ is the total number of observations, $Y_{i}^{\text {obs }}$ is the observed value for the $i$ th step, $Y_{i}^{\text {sim }}$ is the simulated value, $Y^{\text {mean }}$ is the mean value for all the observed value (Moriasi et al., 2007). Here, a NSE value of unity represents the optimal value, while the optimal value is zero for the PBIAS, with low-magnitude values indicating an accurate simulation. These modeling indices are evaluated for checking the accuracy of the time series of the estimated downward longwave radiation.

\section{Data quality control}

The data quality was checked for the entire observation period, and errors were deleted that resulted from maintenance activities or abnormal system behavior and marked as missing values in the EDP database, with Table 2 showing the 
Table 2. Parameter information within the EDP database. Locations A, B and C are located within the observation site of the EDP department as shown in Fig. 1.

\begin{tabular}{|c|c|c|c|c|c|c|c|}
\hline Item & Unit & $\begin{array}{l}\text { Height } \\
\text { (m) }\end{array}$ & Period & $\begin{array}{r}\text { Data coverage } \\
(\%)\end{array}$ & Average & Maximum & Minimum \\
\hline Shortwave downward radiation ${ }^{\mathrm{a}}$ & $\mathrm{W} \mathrm{m}^{-2}$ & 1.5 & $1981 \sim a$ & 94.64 & 146.63 & 356.50 & 3.50 \\
\hline Net radiation & $\mathrm{W} \mathrm{m}^{-2}$ & 1.5 & $1981 \sim$ & 93.84 & 67.39 & 237.20 & -15.00 \\
\hline Longwave downward radiation ${ }^{\mathrm{b}}$ & $\mathrm{W} \mathrm{m}^{-2}$ & 1.5 & $2002-2007^{b}$ & 84.75 & 346.51 & 450.75 & 227.37 \\
\hline Air temperature_Layer1_average ${ }^{\mathrm{a}}$ & ${ }^{\circ} \mathrm{C}$ & 1.6 & $1981 \sim$ & 95.58 & 13.93 & 31.10 & -5.30 \\
\hline Air temperature_Layer1_maximum ${ }^{a}$ & ${ }^{\circ} \mathrm{C}$ & 1.6 & $1981 \sim$ & 98.26 & 19.06 & 37.40 & -0.60 \\
\hline Air temperature_Layer1_minimum ${ }^{\mathrm{a}}$ & ${ }^{\circ} \mathrm{C}$ & 1.6 & $1981 \sim$ & 97.30 & 9.03 & 26.70 & -11.30 \\
\hline Air temperature_Layer2 & ${ }^{\circ} \mathrm{C}$ & 12.5 & $1981 \sim$ & 97.79 & 14.23 & 31.10 & -3.80 \\
\hline Air temperature_Layer3 & ${ }^{\circ} \mathrm{C}$ & 29.5 & $1981 \sim$ & 96.11 & 14.51 & 31.20 & -3.00 \\
\hline Dew point temperature_Layer1 & ${ }^{\circ} \mathrm{C}$ & 1.6 & $1981 \sim$ & 95.51 & 8.86 & 26.30 & -14.70 \\
\hline Dew point temperature_Layer2 & ${ }^{\circ} \mathrm{C}$ & 12.5 & $1981 \sim$ & 89.46 & 8.68 & 27.50 & -19.50 \\
\hline Dew point temperature_Layer3 & ${ }^{\circ} \mathrm{C}$ & 29.5 & $1981 \sim$ & 89.60 & 8.53 & 27.30 & -15.80 \\
\hline Soil temperature_Layer1 & ${ }^{\circ} \mathrm{C}$ & -0.02 & $1981 \sim$ & 97.45 & 14.79 & 32.30 & -1.50 \\
\hline Soil temperature_Layer2 & ${ }^{\circ} \mathrm{C}$ & -0.10 & $1981 \sim$ & 97.73 & 14.72 & 30.30 & 0.60 \\
\hline Soil temperature_Layer3 & ${ }^{\circ} \mathrm{C}$ & -0.50 & $1981 \sim$ & 92.50 & 14.95 & 25.90 & 3.10 \\
\hline Soil temperature_Layer4 & ${ }^{\circ} \mathrm{C}$ & -1.00 & $1981 \sim$ & 97.63 & 14.78 & 25.20 & 5.00 \\
\hline Sensible heat flux & ${ }^{\circ} \mathrm{Cm} \mathrm{s}^{-1}$ & 1.6 & $1981 \sim$ & 90.91 & 0.01 & 0.07 & -0.03 \\
\hline Soil heat flux & $\mathrm{W} \mathrm{m}^{-2}$ & -0.02 & $1981 \sim$ & 85.13 & -0.34 & 20.00 & -20.00 \\
\hline Wind speed ${ }^{\mathrm{a}}$ & $\mathrm{m} \mathrm{s}^{-1}$ & 1.6 & $1981 \sim$ & 99.44 & 0.97 & 3.80 & 0.16 \\
\hline Relative humidity ${ }^{\mathrm{a}, \mathrm{c}}$ & $\%$ & 1.6 & $2003 \sim$ & $97.17^{\mathrm{b}}$ & 75.25 & 100.10 & 28.11 \\
\hline Precipitation $^{\mathrm{a}}$ & $\mathrm{mm} \mathrm{day}^{-1}$ & 0.5 & $1981 \sim$ & 96.51 & 3.20 & 181.50 & 0.00 \\
\hline Atmosphere pressure & $\mathrm{hPa}$ & 1.6 & $1983 \sim$ & 90.67 & 1010.41 & 1033.60 & 977.30 \\
\hline
\end{tabular}

${ }^{a}$ Data items are compared with data from the Japan Meteorological Agency (JMA_Tateno). ${ }^{b}$ The data coverage for relative humidity was estimated starting in 2003. ${ }^{c}$ The observation of longwave downward radiation was between 2002 and 2007. Data coverage, average, maximum and minimum were determined using estimated longwave radiation based on other observation items. The estimated longwave radiation data comprise dates since 1983.

data availability within the database after error deletion. To preserve only original observational data from the EDP site, we do not conduct any gap filling. For most of the parameters, the daily values are average values from hourly data, except the daily precipitation value is the accumulation from hourly data.

This database includes three versions: ver. 1.0, 1.1 and 2.0. For ver. 1.0, the data were collected in integer data format following a former system standard, which applied to the observed data until April 2003. Then, the new system was started from May 2003 and the data set was updated as ver. 1.1. The data quality is guaranteed by the consistent quality control of all raw observation data. The quality control includes removing error data due to instrumental problems and missing data caused by observed values out of the specified range (http://www.ied.tsukuba.ac.jp/yosoku/terc/, last access: 22 October 2018). The data format in ver. 1.1 were established in accordance with Asanuma et al. (2004). Ver. 2.0 is the newest version, which is a comprehensive version containing both ver. 1.0 and ver. 1.1 for the purpose of improving data reliability by performing quality evaluation and quality control. Ver. 2.0 has two main sections. The first section is composed of the hourly, monthly and annual average values with highly consistent quality control from August 1981 to December 2005. The other one is com- posed of the raw data, which include data in time frequencies of $30 \mathrm{~min}, 60 \mathrm{~min}, 24 \mathrm{~h}$ and $10 \mathrm{~s}$ from 2003 to the present (http://www.ied.tsukuba.ac.jp/yosoku/kansoku/rawdata/, last access: 22 October 2018).

\subsection{Comparison with the Japan Meteorological Agency}

After the deletion of error values, the reliability of the observations from the EDP database is assessed with respect to the reference database from the nearest local meteorological agency in Tateno, which belongs to the Japan Meteorological Agency. The Tateno observations are at a height of $2 \mathrm{~m}$ above ground level, with only a few items available for data-quality checking, including shortwave radiation, air temperature (average, maximum and minimum), wind speed, relative humidity and precipitation, at a daily resolution between 1981 and 2017 (see Table 2, Fig. 2). For the EDP database, observations from the $1.6 \mathrm{~m}$ height are compared with the Tateno data, with the data at other heights compared with the adjacent measurement heights. Both of these two data sets are compared in Fig. 2 along with the corresponding values of $R^{2}$.

As the value of $R^{2}>0.99$ for the average, maximum and minimum values of the air temperature in correlations between the Tateno and EDP databases, a high similarity ex- 

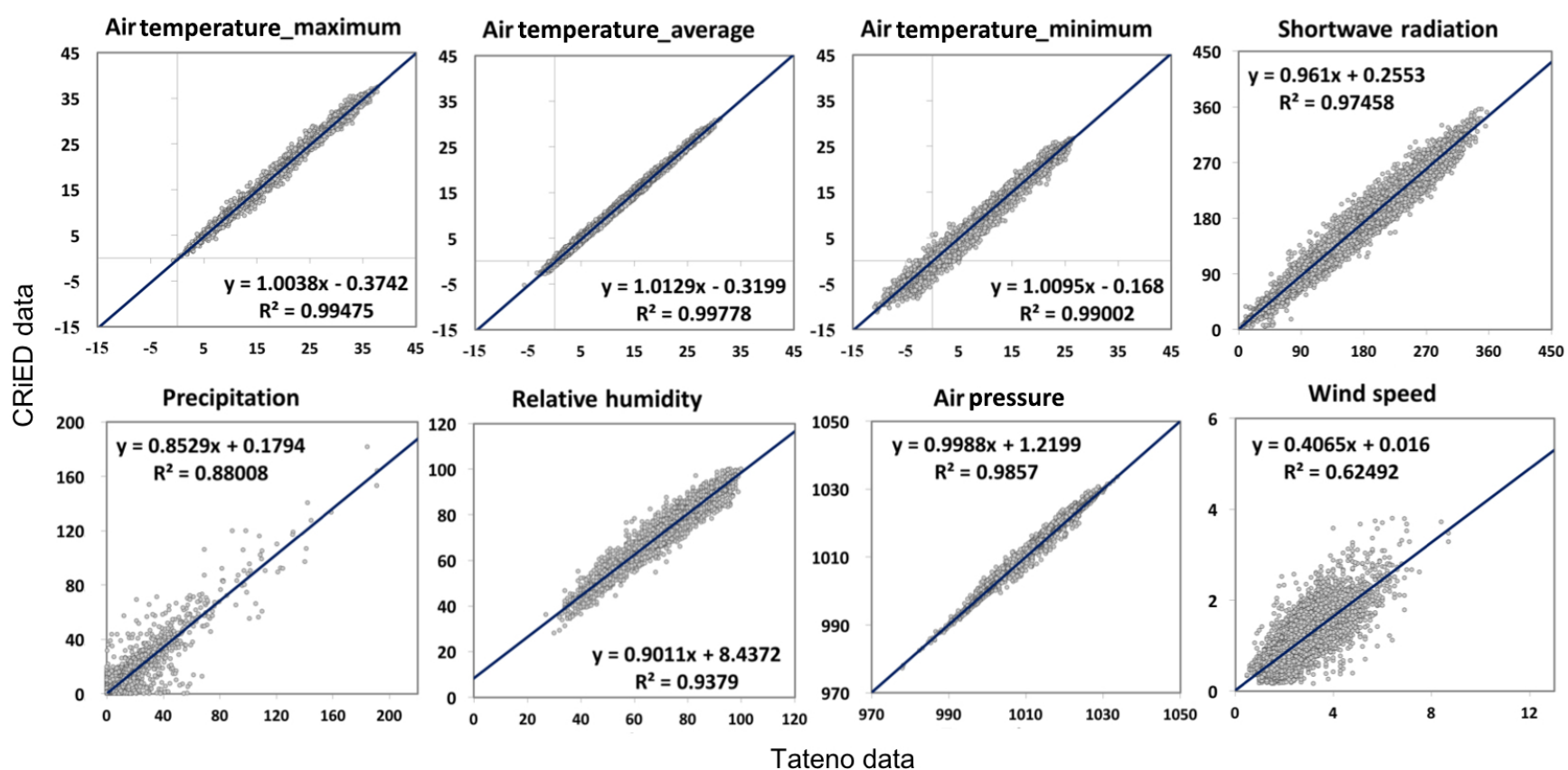

Figure 2. Comparisons of the EDP data with the Tateno data from the Japan Meteorological Agency from 1981 to 2017 . Further parameter information is found in Table 2 .

ists between the two closely located stations separated by $<10 \mathrm{~km}$ and an elevation difference of $1.8 \mathrm{~m}$ (the Tateno and EPD sites are $25.2 \mathrm{~m}$ and $27 \mathrm{~m}$ a.s.l., respectively). However, slight differences between these two databases were found, which is caused by the different land surface, such as the presence of different vegetation and artificial structures. Because of the diverse land-surface cover and varied moisture distribution, the value of the relative humidity RH differs slightly, but is still well correlated. Differences in shortwave radiation between the EDP and Tateno are mainly governed by solar radiation, whereas absorption and reflection may be caused by atmospheric conditions (clouds). Overall, most of the variables are highly correlated, except wind speed and precipitation.

According to the regression analysis, a lower correlation is found for the precipitation and wind speed between these two stations (Fig. 2), because of the highly local characteristics of these two variables. In the case of the wind speed, the sensor of the EDP site located at a height of $1.6 \mathrm{~m}$ is surrounded by grass during the growing season and prior to mowing when the height of the grass reaches $1.8 \mathrm{~m}$, which generates enhanced local turbulence, resulting in a reduced wind speed. The precipitation amounts are significantly affected by the local conditions depending on the humidity, temperature, cloud distribution and wind speed (Shuttleworth, 2011). In general, after error deletion, the EDP database compares reasonably well to the Tateno database.

\subsection{Downward longwave radiation}

The downward longwave radiation was calculated by using the method introduced in Sect. 2.2.1 as estimated from routine meteorological observations from 1983 to 2017 and compared with a 5 -year data set collected by the EDP department from 2002 to 2006 (Fig. 3), giving $R^{2}=0.974$, $\mathrm{NSE}=0.947$ and PBIAS $=1.486$ and indicating good agreement of the estimated values with the observed values according to Moriasi et al. (2007). Although the estimated values are slightly higher than the observed values, this slight bias of estimation is consistent with the statement by Kondo et al. (1994) regarding the effect of winter resulting from the presence of snow. However, most of the estimated values correspond well with the observed values.

\subsection{Statistical analysis}

Plotted in Fig. 4 are daily observed values of the air and soil temperatures for all layers, the precipitation, air pressure, humidity, longwave radiation, solar radiation, net radiation $\left(R_{\mathrm{n}}\right)$, the soil heat flux $(G)$ and sensible heat flux $(H)$ af ter data quality control. For each soil layer, the temperature varies between the deep and shallow layers, with the longterm-average values varying from 14.7 to $15^{\circ} \mathrm{C}$, the maximum values from 25.2 to $32.3{ }^{\circ} \mathrm{C}$ and the minimum values from -1.5 to $5^{\circ} \mathrm{C}$. A regular annual variation is found for the four soil layers, with the response of the deeper layers being slower than the shallow layers. The larger amplitude variation is evident in the shallowest soil layer, with the amplitude gradually decreasing for deeper soil layers. Some ex- 


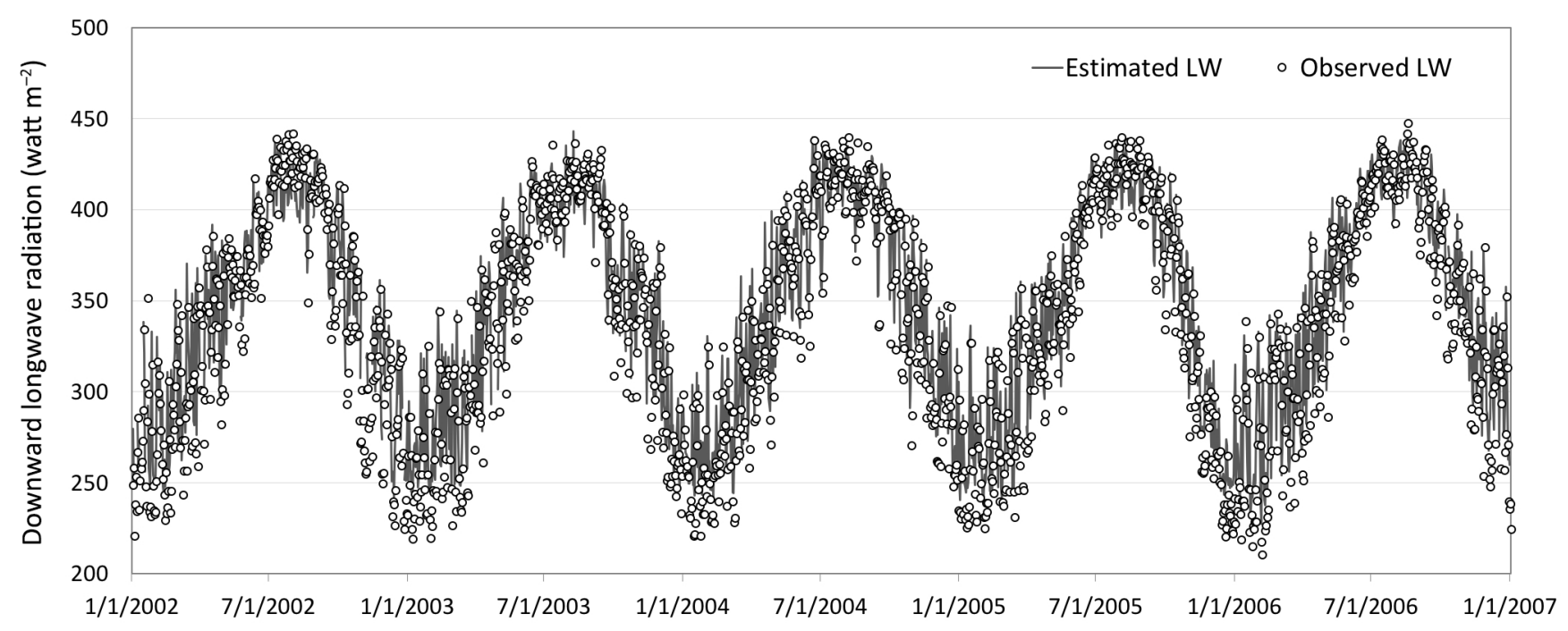

Figure 3. Comparison of estimated and observed downward longwave radiation at the EDP site from 1 January 2002 to 31 st December 2006.

tremely high values occurred in 1990, 1991 and 2005, and extremely low values were found from 1983 to 1985 and 2011 to 2013. In contrast to the temperature of the different soil layers, the three air-temperature measurements show similar patterns of variation, with the 37-year average values for the heights of $1.6,12.5$ and $29.5 \mathrm{~m}$ corresponding to $13.9,14.2$ and $14.5^{\circ} \mathrm{C}$, respectively. The maximum value is $31.1^{\circ} \mathrm{C}$ for all three layers, but the minimum values show obvious differences of $-5.3{ }^{\circ} \mathrm{C}$ at $1.6 \mathrm{~m},-3.8^{\circ} \mathrm{C}$ at $12.9 \mathrm{~m}$ and $-3.0^{\circ} \mathrm{C}$ at $29.5 \mathrm{~m}$. For the dew point temperature, the three layers show very similar ranges of observation values. From 1.6 to $29.5 \mathrm{~m}$, the long-term average varies from 8.5 to $8.9^{\circ} \mathrm{C}$, the maximum value from 26.3 to $27.9^{\circ} \mathrm{C}$ and the minimum value from -14.7 to $-19.5^{\circ} \mathrm{C}$. The minimum values for the air and dew point temperature at $1.6 \mathrm{~m}$ are more different than the other layers, since the $1.6 \mathrm{~m}$ measurement height is more easily affected by any dramatic temperature or moisture exchanges with the ground.

The 37-year average value of precipitation is $1183.8 \mathrm{~mm} \mathrm{year}^{-1}$, and the maximum precipitation event occurred in 1986 with an amount of $181.5 \mathrm{~mm} \mathrm{day}^{-1}$. The relative humidity takes an average value of $75.2 \%$ for the 37 -year period. The long-term-average value of the air pressure is $1010.4 \mathrm{hPa}$.

The long-term-average value of the net radiation is $66.9 \mathrm{~W} \mathrm{~m}^{-2}$, while the maximum value is $237.2 \mathrm{~W} \mathrm{~m}^{-2}$, and the minimum is $-15 \mathrm{~W} \mathrm{~m}^{-2}$. The interannual variation indicates an increasing tendency for both the summer and winter from 1981 to 2004, but which has reduced since 2005. The average value of the shortwave radiation is about $146.6 \mathrm{~W} \mathrm{~m}^{-2}$, while the maximum value is $356.5 \mathrm{~W} \mathrm{~m}^{-2}$, and the minimum is $-3.5 \mathrm{~W} \mathrm{~m}^{-2}$. The average value of the longwave radiation is $346.5 \mathrm{~W} \mathrm{~m}^{-2}$, while the maximum value is $450.8 \mathrm{~W} \mathrm{~m}^{-2}$, and the minimum is $227.4 \mathrm{~W} \mathrm{~m}^{-2}$.
The soil heat flux and sensible heat flux show less regular variations compared with the values of the temperatures presented above, because of the difficulties in the accurate monitoring of the soil heat flux resulting from the high spatial variation in the soil properties. Furthermore, the soil heat flux is easily influenced by the soil temperature, air temperature and heat capacity as well as the thermal peculiarities of heterogeneous soil layers. However, since the observation of these thermal components is rare, they are highly valuable for hydrometeorological investigations. Further analysis of the database is highly encouraged for specific research topics.

\section{Results}

The complete long-term hydrometeorological data set at our grassland site represents a valuable resource for climate studies. For example, Duan et al. (2015) demonstrated the uniqueness of this area, which indicates that changes in the precipitation amounts in Japan are in the opposite direction to the extremes seen in the surrounding countries. Moreover, the database is capable of providing data for assessing both the energy and water budgets. Here, the main tendencies in the last 37 years are summarized in Fig. 5, where the annual values represent the years with data availability $>90 \%$ (328 days for 1 year), because gap filling has not been performed.

Based on the annually averaged values, most variables show a positive trend, except the soil temperature, soil heat flux, wind speed and precipitation, which show a slightly negative trend. First, the shortwave, longwave and net radiation increased between 1981 and 2017 (Fig. 5a-c). The shortwave radiation was compared with data from the Tateno database above, from which a similar positive tendency was 

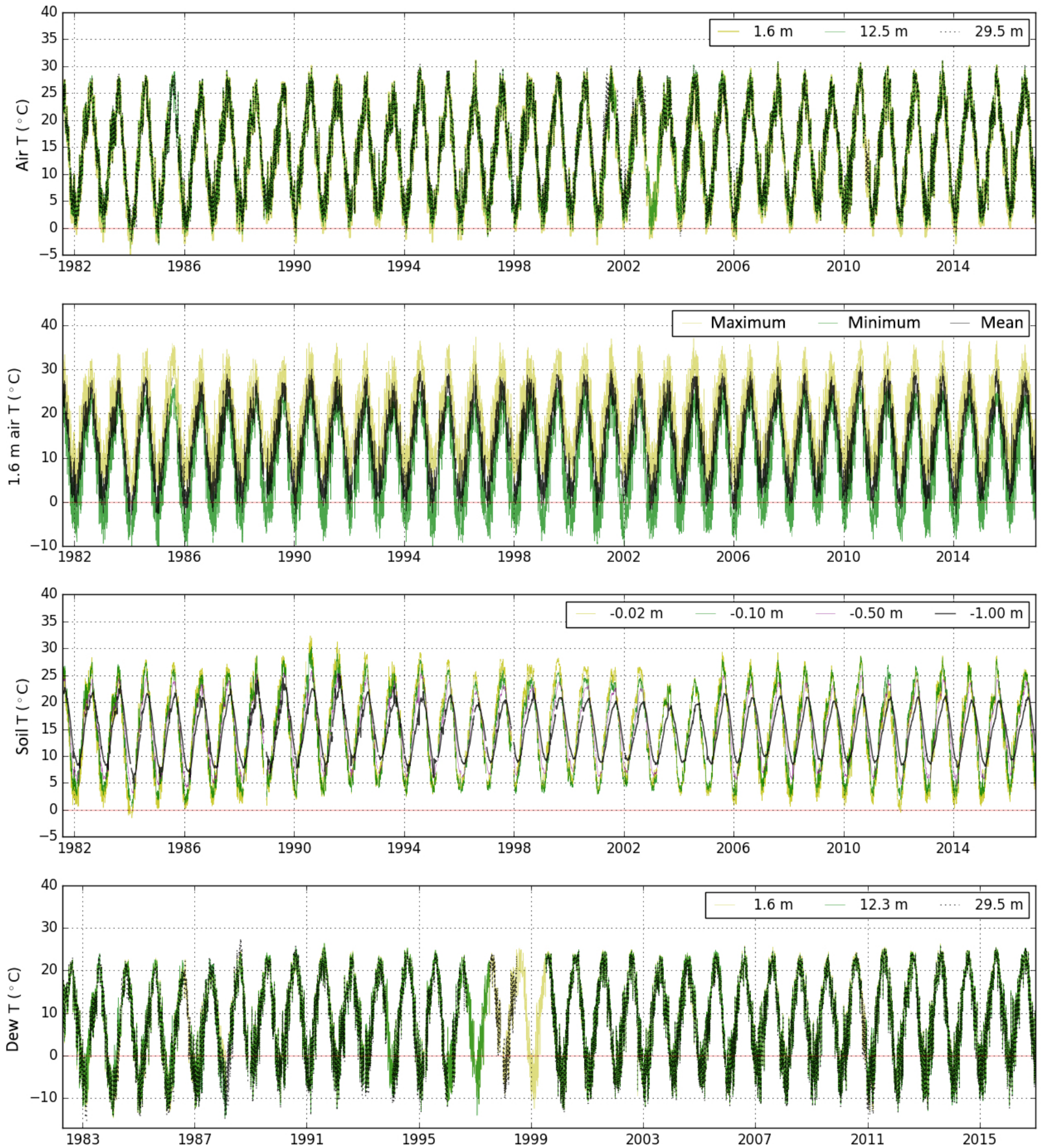

Figure 4.

found. That the estimated longwave radiation has a positive trend is consistent with the air-temperature trend with reference to the Stefan-Boltzmann law (Shuttleworth, 2011). Since the shortwave radiation has increased, it is reasonable to expect the net radiation to have increased as well, because the balance of net radiation is governed by the balance of the shortwave and longwave radiation. An observed positive air-temperature trend is evident since 1981 (Fig. 5j), which is consistent with the global trend related to climate change and an increasing temperature. The average, maximum and min- 

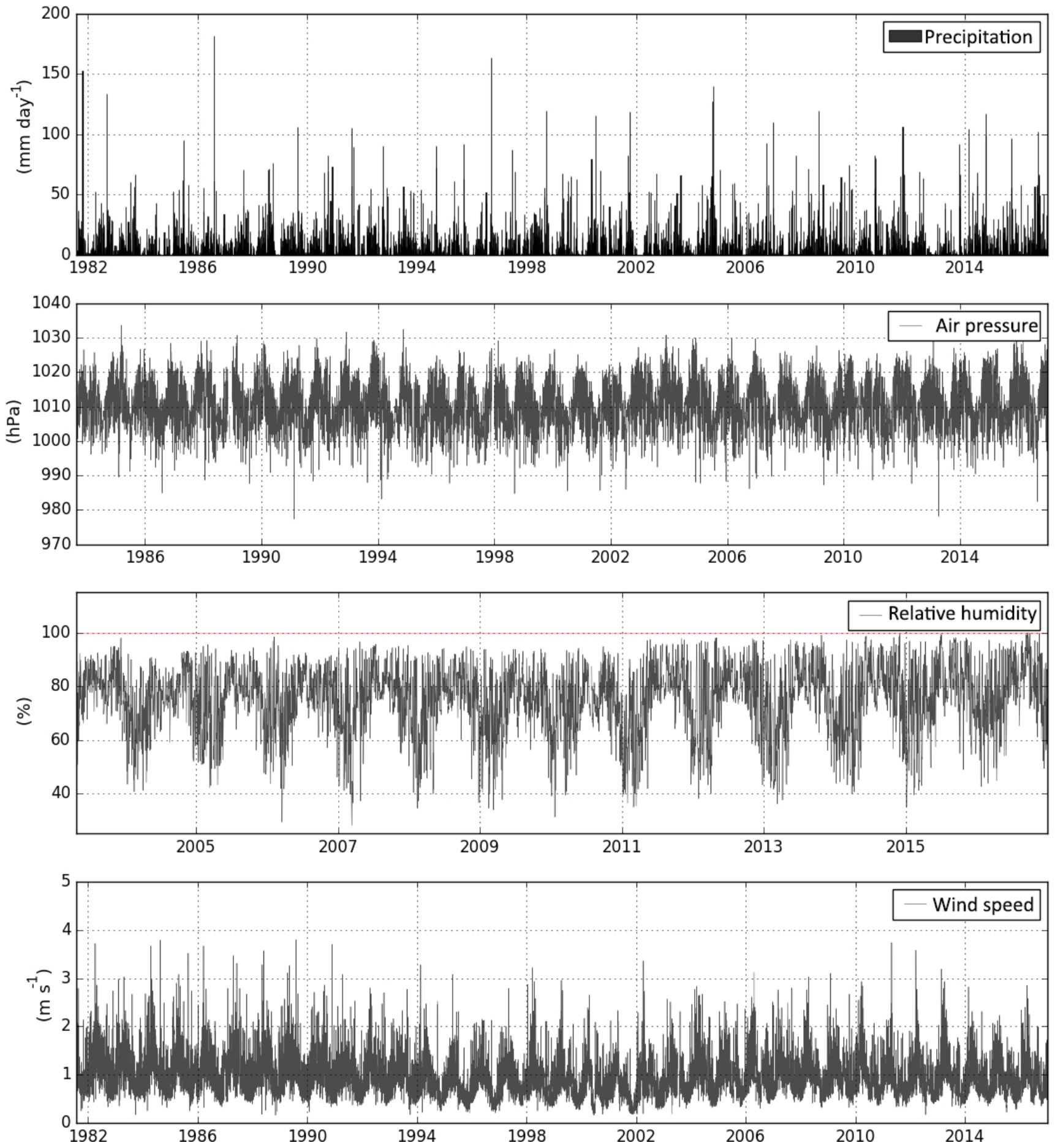

Figure 4.

imum values of the air temperature all show a positive trend with an increase of $0.04{ }^{\circ} \mathrm{C}_{\text {year }}{ }^{-1}$. Here, the minimum value increased more slowly than the other two statistics, because the minimum air temperature is highly affected by urbanization (Kondo et al., 1994), where the main construction period of Tsukuba occurred within the 1980s and slowed down thereafter, so that the minimum air temperature shows a relatively smaller positive trend compared with the maximum and average values. The dew point temperature mainly followed a similar positive trend as the air temperature, with similarly increasing values at all three heights, including the first height, which is often surrounded by grass (see 

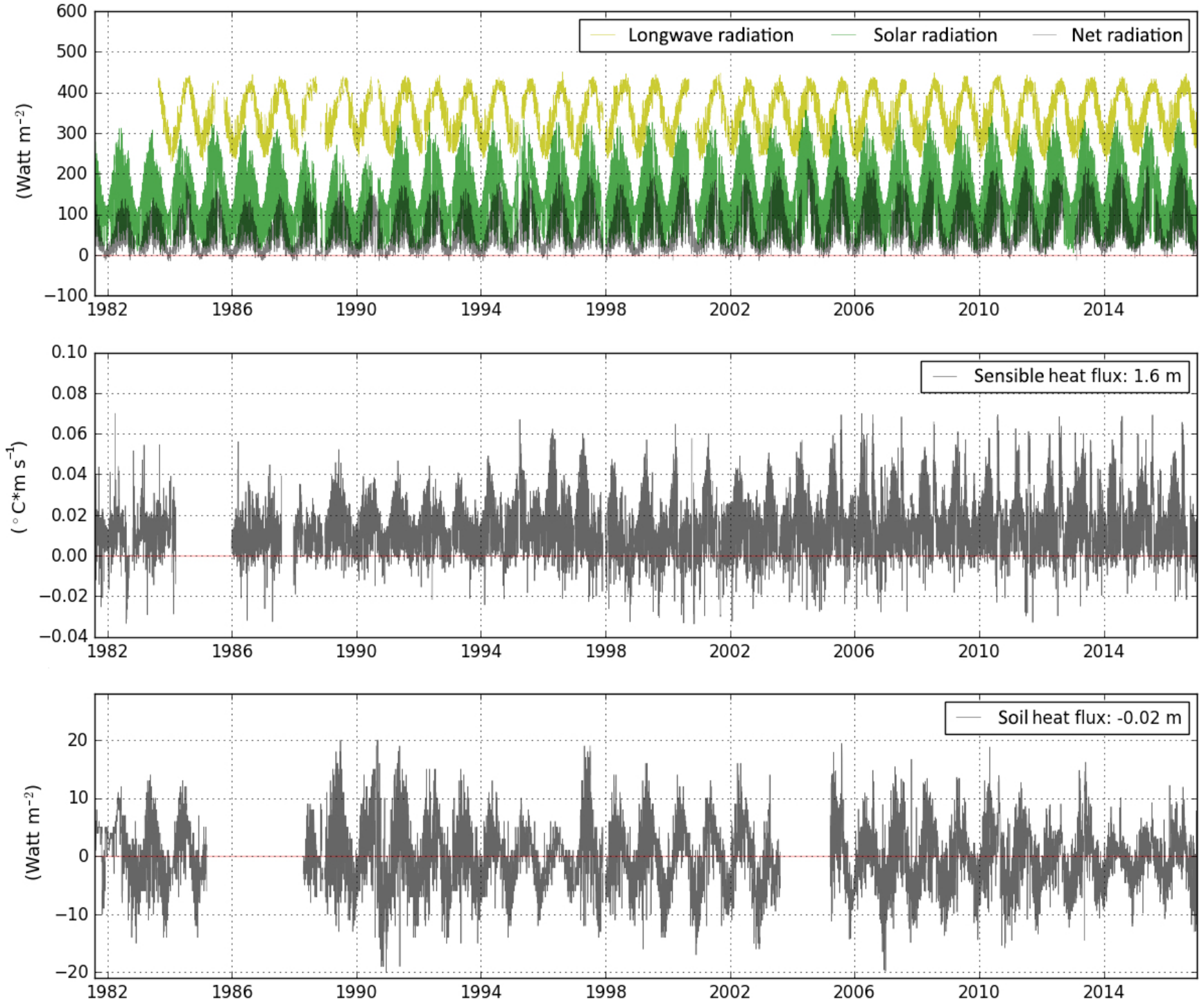

Figure 4. Daily observed values of the air temperatures for all layers, maximum, minimum and mean air temperature at a height of $1.6 \mathrm{~m}$, soil and dew temperatures for all layers, the precipitation, air pressure, humidity, wind speed, longwave radiation, solar radiation, net radiation, sensible heat flux and the soil heat flux at the EDP site from 1981 to 2017.

Figs. $5 \mathrm{k}, 1)$. The variation in the surface soil layer $(-0.02 \mathrm{~m})$ shows a higher amplitude than the lower soil layers, which are more exposed to the energy exchange occurring in the lower atmosphere, and since the EDP site is covered by bushy grass, the energy transport received has a strong influence. Therefore, the temperature of the soil layer does not show any simple deviation from the annual average values (Fig. 5l). The explanation of the negative tendency of the soil heat flux (Fig. 5e) relates to the energy balance as pointed out by Brutsaert (1982), where $R_{\mathrm{n}}=L_{e} E+H+G, L_{e}$ is the latent heat of vaporization, and $L_{p}$ is the thermal conversion factor for the fixation of carbon dioxide, so that the variation in the soil heat flux $\left(G=R_{\mathrm{n}}-L_{e} E-H\right)$ is directly related to the variation in the net radiation, and the latent and sensible heat fluxes. The tendency of evapotranspiration is possibly positive since the temperature, which is the dominant factor, shows a significant positive trend. Furthermore, although there is a slightly positive trend of net radiation as well as a negative trend of the sensible heat flux, the soil heat flux shows a negative trend. The corresponding increase in potential evapotranspiration is very possibly caused by the air temperature rising, which is in accordance with global climate change. As the temperature is the most important parameter for evapotranspiration, the increase in temperature probably leads to an increase in evapotranspiration, meaning the decrease in the soil heat flux is reasonable, although no data exist for the observations of the latent heat flux. The sensible heat flux and the relative humidity show positive 

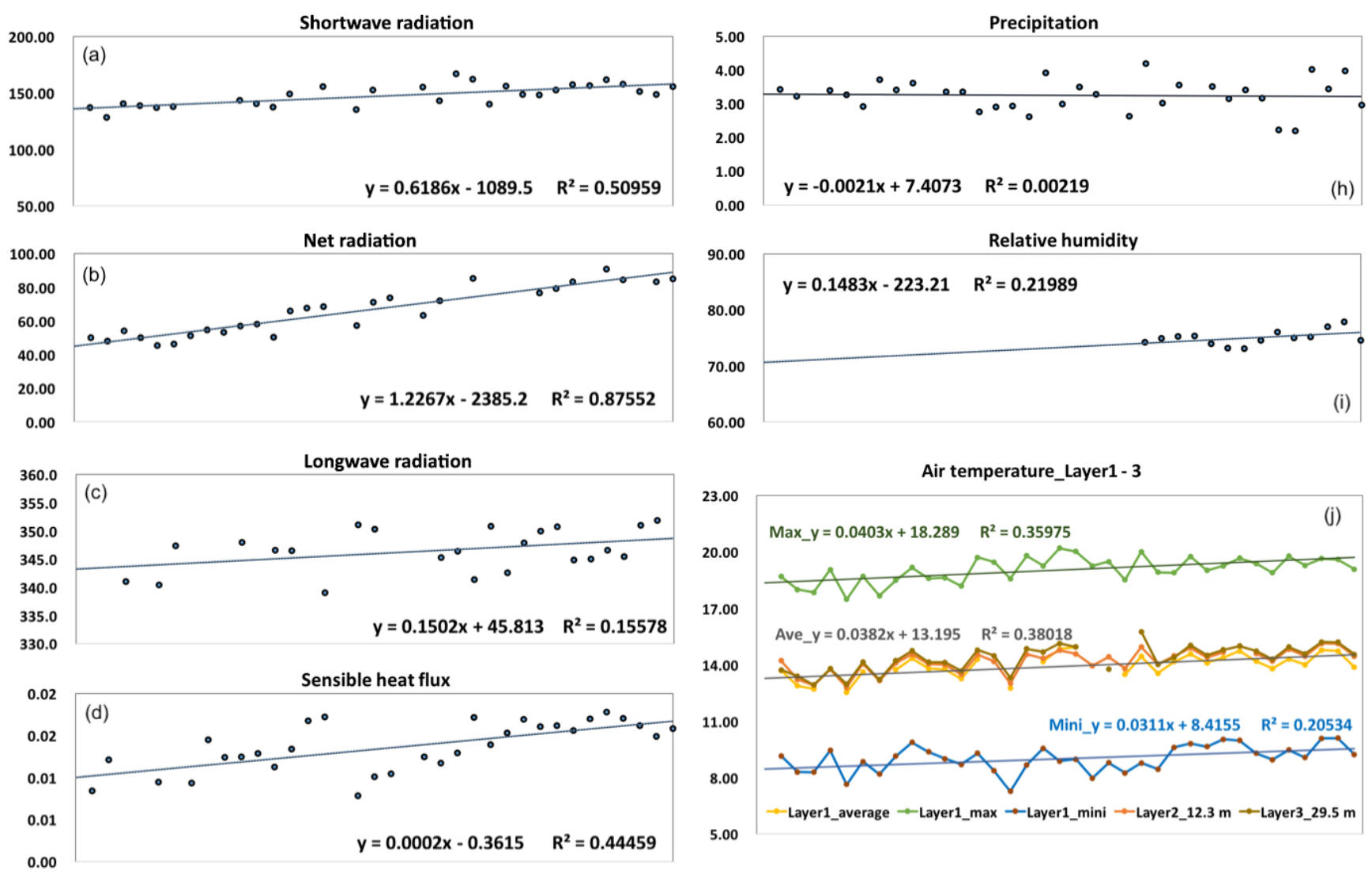

Soil heat flux

Dew temperature_Layer1 - 3
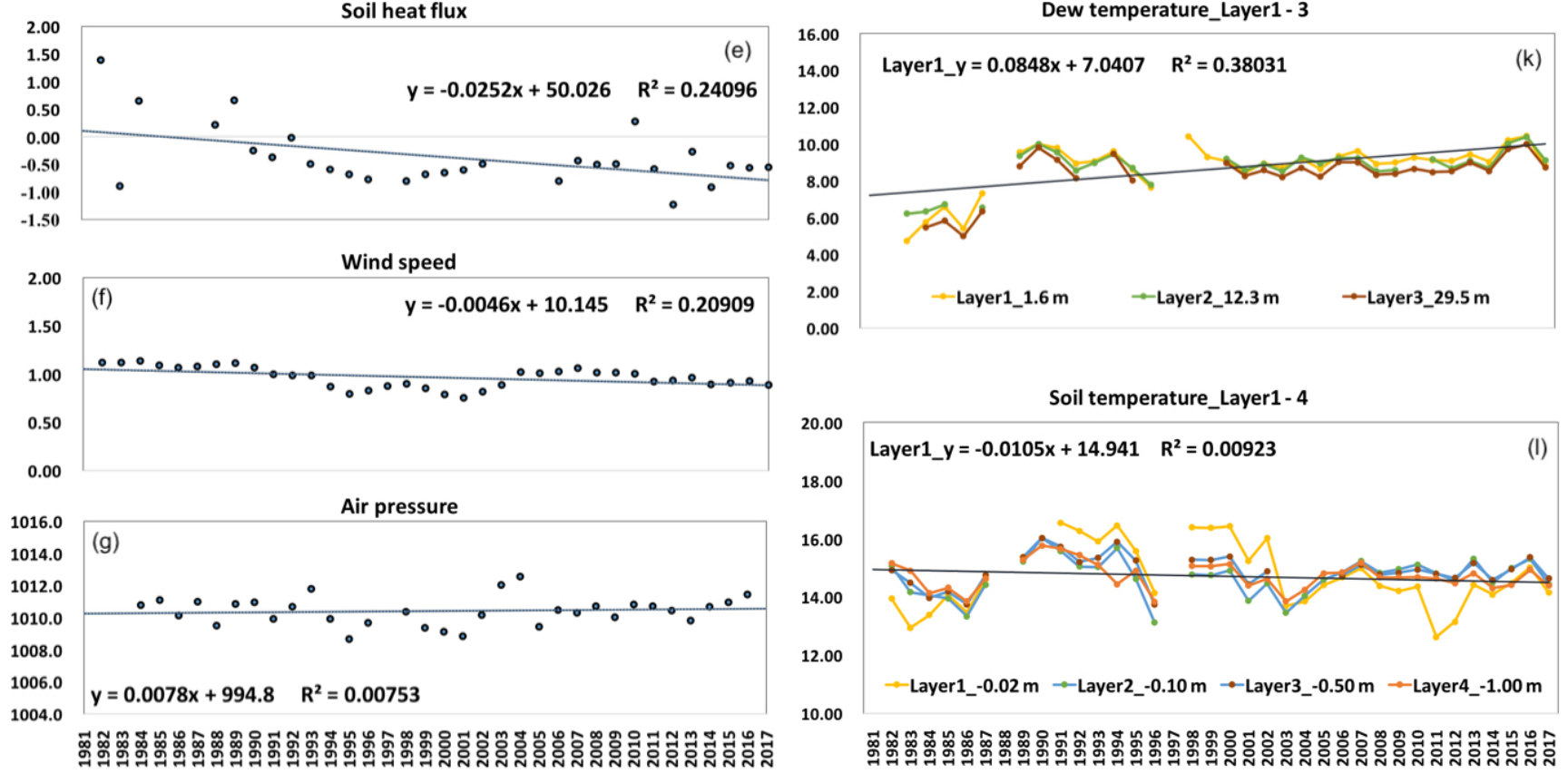

Figure 5. Annual average values of the observational database showing the (a) shortwave radiation $\left(\mathrm{W} \mathrm{m}^{-2}\right),(\mathbf{b})$ net $^{-1}$ adiation $\left(\mathrm{W} \mathrm{m}^{-2}\right)$, (c) longwave radiation $\left(\mathrm{W} \mathrm{m}^{-2}\right)$, (d) sensible heat flux $\left({ }^{\circ} \mathrm{C} \mathrm{m} \mathrm{s}^{-1}\right)$, (e) soil heat flux $\left(\mathrm{W} \mathrm{m}^{-2}\right)$, (f) wind speed $\left(\mathrm{m} \mathrm{s}^{-1}\right)$, $(\mathrm{g})$ air pressure $(\mathrm{hPa})$, (h) precipitation $\left(\mathrm{mm} \mathrm{day}^{-1}\right)$, (i) relative humidity $(\%)$, (j) average, maximum and minimum air temperature $\left({ }^{\circ} \mathrm{C}\right)$ at a height of $1.6 \mathrm{~m}$, with the average values at the heights of 12.3 and $29.5 \mathrm{~m}$, (k) dew point temperature $\left({ }^{\circ} \mathrm{C}\right)$ at heights of $1.6,12.3$ and $29.5 \mathrm{~m}$, and $(\mathbf{l})$ soil temperature $\left({ }^{\circ} \mathrm{C}\right)$ at the depths of $0.02,0.1,0.5$ and $1 \mathrm{~m}$. 
trends (Fig. 5d, i). The main variation in the trend of precipitation is relatively moderate because of the more extreme low and high values recorded in recent decades, which is consistent with the more extreme precipitation observed globally (Donat et al., 2016, Fig. 5h). Compared with precipitation, a similar trend may be found in the relative humidity, although the analysis period is relatively short, beginning in 2004 (Fig. 5i). For the wind speed (Fig. 5f), there is negative tendency shown for the long-term observations, which is easily affected by the variation in the surrounding land cover. During these decades, two minor decreases in the signal are found between 1993 and 2002, and a decrease is also found in the value of the air pressure (Fig. $5 \mathrm{~g}$ ).

\section{Data availability}

The database described here has a digital object identifier (https://doi.org/10.24575/0001.198108, Asanuma and Ma, 2017) and is freely available at the home page of the EDP data center (https://doi.org/10.24575/0001.198108). The data must be fully referenced for every use as introduced at http: //www.ied.tsukuba.ac.jp/en/edps/database-doi/ (last access: 22 October 2018). Supplemental materials may be found by checking the observational data website at http://www. ied.tsukuba.ac.jp/yosoku/kansoku/ (last access: 22 October 2018). Maintenance information is found from the database $\log$ at http://www.ied.tsukuba.ac.jp/yosoku/kansoku/hojyo_ log/ (last access: 22 October 2018).

\section{Conclusions}

A high-quality database covering 37 years is presented from the north-east of Japan, encompassing four observational frequencies, three measurement levels above ground and four layers below the ground. The daily and annual average values were presented, including the daily values of shortwave radiation, average, maximum and minimum air temperatures, wind speed, relative humidity and precipitation, which were compared with data from the local meteorological agency at Tateno for validation of the data quality. Highly valuable data are also presented, such as for the net radiation, soil temperature at four depths, the air and dew point temperatures at three heights, the net radiation, soil heat flux and sensible heat flux, especially because the soil heat flux and sensible heat flux are relatively rarely observed or available. Furthermore, a time series of longwave radiation has been generated for this site based on the reliable observations.

The annual average values were analyzed for the years with data availability $>90 \%$. The annual average values show a positive tendency for the shortwave radiation, net radiation, longwave radiation, sensible heat flux, air pressure, relative humidity, the air and dew point temperatures at the three heights and a negative trend of the soil heat flux, wind speed, precipitation and soil temperature. These trends provide an important database and evidence for understanding the variations occurring within the study area. At the same time, the specific characteristics of the database may be found for the grassland with respect to the values of the wind speed and precipitation based on the comparisons between the daily values from the EDP database and Tateno as well as the regression of annual average values. As the in situ observational site and database have contributed to many previous studies, we shall continue to maintain it, and we wish to make the data available for further research and analysis.

Supplement. The supplement related to this article is available online at: https://doi.org/10.5194/essd-10-2295-2018-supplement.

Author contributions. JA created the observation system and data collection system, and controls the measurement. WM prepared the database and wrote this manuscript. JX provided the theoretical support of downward longwave radiation. WM and JX estimated the downward longwave radiation. JA and YO designed this work. All authors provided critical feedback and helped to shape the research, analysis and manuscript.

Competing interests. The authors declare that they have no conflict of interest.

Acknowledgements. This study was supported by "Interdisciplinary Project on Environmental Transfer of Radionuclides". The authors would like to acknowledge Prof. Tsutomu Yamanaka for his valuable suggestions. We thank Tomohiro Sekiguchi and Kentaro Aida for their assistance in the system maintenance. We thank Hideo Iijima, Shiraishi Izumi and Naomi Nakajima for providing digital and paper-based bulletins for this review. We thank two anonymous reviewers for their thoughtful and constructive comments, which helped to improve the quality of this work.

Edited by: David Carlson

Reviewed by: two anonymous referees

\section{References}

Asanuma, J. and Ma, W.: Heat and Water Balance Measurement System, Center for Research in Isotopes and Environmental Dynamics at University of Tsukuba, https://doi.org/10.24575/0001.198108, 2017.

Asanuma, J., Nohara, D., Hara, M., and Yorisaki, T.: The Third Generation of the Data Collecting System for Meteorological and Hydrological Measurements, Bulletin of the TERC, the University of Tsukuba, 5, 157-174, https://doi.org/10.15068/00146972, 2004.

Brutsaert, W.: Evaporation into the Atmosphere, in: Theory, History and Applications, Kluwer Academic, Dordrecht, 1, 2-3, 1982. 
Donat, M. G., Lowry, A. L., Alexander, L. V., O'Gorman, P. A., and Maher, N.: More extreme precipitation in the worlds dry and wet regions, Nat. Clim. Change, 6, 508-513, https://doi.org/10.1038/nclimate2941, 2016.

Duan, W., He, B., Takara, K., Luo, P., Hu, M., Alias, N. E., and Nover, D.: Changes of precipitation amounts and extremes over Japan between 1901 and 2012 and their connection to climate indices, Clim. Dynam., 45, 2273-2292, https://doi.org/10.1007/s00382-015-2778-8, 2015.

Godsey, S. E., Marks, D., Kormos, P. R., Seyfried, M. S., Enslin, C. L., Winstral, A. H., McNamara, J. P., and Link, T. E.: Eleven years of mountain weather, snow, soil moisture and streamflow data from the rain-snow transition zone - the Johnston Draw catchment, Reynolds Creek Experimental Watershed and Critical Zone Observatory, USA, Earth Syst. Sci. Data, 10, 1207-1216, https://doi.org/10.5194/essd-10-1207-2018, 2018.

Grayson, R. and Blöschl, G. (Eds.): Spatial Patterns in Catchment Hydrology: Observations and Modelling, Cambridge University Press, Cambridge, 2001.

Guillevic, P. C., Privette, J. L., Coudert, B., Palecki, M. A., Demarty, J., Ottle, C., and Augustine, J. A.: Land Surface Temperature product validation using NOAA's surface climate observation networks - Scaling methodology for the Visible Infrared Imager Radiometer Suite (VIIRS), Remote Sens. Environ., 124, 282-298, https://doi.org/10.1016/j.rse.2012.05.004, 2012.

Gupta, H. V., Sorooshian, S., and Yapo. P. O.: Status of automatic calibration for hydrologic models: Comparison with multilevel expert calibration, J. Hydrol. Eng., 4, 135-143, 1999.

Hamada, Y., Fernando, A. R. I., and Tanaka, T.: Physical Properties of Soils of Red Pine Forest and Heat Balance and Water Balance Experiment Field in Environmental Research Center, University of Tsukuba, Bulletin of the TERC, the University of Tsukuba, 23, 1-10, 1998.

Hayashi, Y., Harazono, Y., Nasuno, M., and Toritani, H.: Dynamic response of a Red Pine Canopy to changes of the Outside Environment. 1. Characteristics of temperature field within and above a Red pine canopy, Bulletin of the ERC, the University of Tsukuba, 13, 97-103, 1989.

Hirschi, M. and Seneviratne, S. I.: Basin-scale water-balance dataset (BSWB): an update, Earth Syst. Sci. Data, 9, 251-258, https://doi.org/10.5194/essd-9-251-2017, 2017.

Hiyama, T., Sugita, M., and Mikami, M.: Comparisons of the Latent Heat Fluxes Evaluated by a Weighing Lysimeter and an Energy Balance Method, Bulletin of the TERC, the University of Tsukuba, 18, 41-53, 1993.

Imasu, F., Mo, W., Kato, M., and Oikawa, T.: Seasonal changes in LAI and aboveground biomass of a $\mathrm{C}_{3} / \mathrm{C}_{4}$ mixed grassland in 2001 in the Terrestrial Environment Research Center, Bulletin of the TERC, the University of Tsukuba, 3, 17-25, 2002.

Iwata, H. and Sugita, M.: Correction of sensible heat flux measurement errors using a universal function of standard deviation of vertical wind velocity, Bulletin of the TERC, the University of Tsukuba, 6, 87-97, https://doi.org/10.15068/00147136, 2006.

Jackson, T. J., Vindlish, R., and Cosh, M.: Validation of AMSRE Soil Moisture Products Using In Situ Observations, Journal of The Remote Sensing Society of Japan, 29, 263-270, https://doi.org/10.11440/rssj.29.263, 2009.

Kawamura, R.: Studies on Global Climate System, Bulletin of the ERC, the University of Tsukuba, 15, 109-115, 1991.
Kondo, J.: Meteorology of the water environment, Asakura Press, 86-91, 1994 (in Japanese).

Kondo, J. and Xu, J.: Seasonal Variations in the Heat and Water Balances for Nonvegetated Surfaces, J. Appl. Meteorol., 36, 16761695, 1997.

Kormos, P. R., Marks, D. G., Seyfried, M. S., Havens, S. C., Hedrick, A., Lohse, K. A., Sandusky, M., Kahl, A., and Garen, D.: 31 years of hourly spatially distributed air temperature, humidity, and precipitation amount and phase from Reynolds Critical Zone Observatory, Earth Syst. Sci. Data, 10, 1197-1205, https://doi.org/10.5194/essd-10-1197-2018, 2018.

Kotada, K. and Hayashi, Y.: Numerical modelling on wind speed profile of vegetation community, Bulletin of the ERC, the University of Tsukuba, 4, p. 102, 1980.

Liang, L., Schwartz, M. D., and Fei, S.: Validating satellite phenology through intensive ground observation and landscape scaling in a mixed seasonal forest, Remote Sens. Environ., 115, 143157, https://doi.org/10.1016/j.rse.2010.08.013, 2011.

Makarieva, O., Nesterova, N., Lebedeva, L., and Sushansky, S.: Water balance and hydrology research in a mountainous permafrost watershed in upland streams of the Kolyma River, Russia: a database from the Kolyma Water-Balance Station, 1948-1997, Earth Syst. Sci. Data, 10, 689-710, https://doi.org/10.5194/essd10-689-2018, 2018.

Moriasi, D. H., Arnold, J. G., Van Liew, M. W., Bingner, R. L., Harmel, R. D., and Veith, T. L.: Model evaluation guidelines for systematic quantification of accuracy in watershed simulations, American Society of Agricultural and Biological Engineers, 50, 885-900, 2007.

Nakagawa, S.: Possibility of Equilibrium Evaporation Model for Estimating Actual Evapotranspiration, Bulletin of the ERC, the University of Tsukuba, 7, 17-26, 1983.

Nasuno, M., Hayashi, Y., Harazono, Y., Nishizawa, T.: Dynamic response of a Red Pine Canopy to changes of the Outside Environment. 3. Turbulence Transport over and within a Red Pine Canopy, Bulletin of the ERC, the University of Tsukuba, 13, 113-121, 1989.

Ohba, M. and Yamanaka, T.: Observational data of heat balance and water balance: 2007, Bulletin of the TERC, the University of Tsukuba, 9, 49-74, https://doi.org/10.15068/00147251, 2008.

Qu, W., Bogena, H. R., Huisman, J. A., Schmidt, M., Kunkel, R., Weuthen, A., Schiedung, H., Schilling, B., Sorg, J., and Vereecken, H.: The integrated water balance and soil data set of the Rollesbroich hydrological observatory, Earth Syst. Sci. Data, 8, 517-529, https://doi.org/10.5194/essd-8-517-2016, 2016.

Saito, M. and Yamanaka, T.: Analysis of Long-term Evapotraspiration Data Observed by Weighing Lysimeter and Its Quality Control, Bulletin of the TERC, the University of Tsukuba, 6, 53-62, https://doi.org/10.15068/00147122, 2005.

Sakura, Y.: Miscellaneous, IV Water balance observation facility, Bulletin of the ERC, the University of Tsukuba, 1, 87-90, 1977.

Sakura, Y.: Soil Water Movement Estimated from Soil Temperature Changes during Infiltration, Bulletin of the ERC, the University of Tsukuba, 3, 33-38, 1979.

Sakura, Y. and Taniguchi, M.: Experiments of rain infiltration on characteristics of soil water movement using a soil column, Geographical Review of Japan, 56, 81-93, https://doi.org/10.4157/grj.56.81, 1983. 
Shimizu, R. and Yamanaka, T.: The Spatial Structure of Isotopic Composition of Atmospheric Water Vapor at Micrometeorological Scale, Bulletin of the TERC, the University of Tsukuba, 6 , 3-9, https://doi.org/10.15068/00147114, 2005.

Shuttleworth, W. J.: Terrestrial Hydrometeolology, Wiley-Black Well, 59-63, 155-174, 2011.

Singh, J., Knapp, H. V., and Demissie, M.: Hydrologic modeling of the Iroquois River watershed using HSPF and SWAT, ISWS CR 2004-08, Champaign, Ill: Illinois State Water Survey, available at: https://pdfs.semanticscholar.org/ 8e94/d50b49c6f1b8ad03d86e8605890f30f25847.pdf (last access: 7 December 2018), 2005.

Sugita, M. and Kotoda, K.: Effects of Soil Water Deficits on Forest Evapotranspiration, Bulletin of the ERC, the University of Tsukuba, 9, 83-88, 1985.

Sugita, M., Degutschi, K., and Kotoda, K.: An Apparatus for Measuring Heat Pulse Velocity and Its Application for Transpiration Flux Estimation - Examples of Measurements in Coniferous and Deciduous Tress, Bulletin of the ERC, the University of Tsukuba, 9, 83-88, 1985.

Tanaka, K. and Oikawa, T.: Seasonal dynamics of LAI in a $\mathrm{C}_{3} / \mathrm{C}_{4}$ co-occurring grassland at the Environmental Research Center (1996, 1997), Bulletin of the ERC, the University of Tsukuba, 23, 87-89, 1998.

Taniguchi, M.: Groundwater Recharge Rates and Soil Temperature in Pasture Land and Pine Forest, Bulletin of the ERC, the University of Tsukuba, 14, 69-74, 1990.

Tase, N. and Majima, M.: Rainfall Simulation in a Red Pine Forest, Bulletin of the ERC, the University of Tsukuba, 7, 9-15, 1983.

Wang, P. and Yamamaka, T.: Application of a two-source model for partitioning evapotranspiration and assessing its controls in temperate grasslands in central Japan, Ecohydrology, 7, 345-353, https://doi.org/10.1002/eco.1352, 2014.
Wang, P., Yamanaka, T., Li, X. Y., and Wei, Z. W.: Partitioning evapotranspiration in a temperate grassland ecosystem: Numerical modeling with isotopic tracers, Agr. Forest Meteorol., 208, 16-31, https://doi.org/10.1016/j.agrformet.2015.04.006, 2015.

Watarai, Y. and Yamanaka, T.: Observational Data of Heat Balance and Water Balance - 2006, Bulletin of the TERC, the University of Tsukuba, 8, 55-80, https://doi.org/10.15068/00147239, 2007.

$\mathrm{Xu}$, J. and Haginoya, S.: An Estimation of Heat and Water Balances in the Tibetan Plateau, Journal of the Meteorological Society of Japan, 79, 485-504, https://doi.org/10.2151/jmsj.79.485, 2011.

Xu, J., Haginoya, S., Masuda, K., and Suzuki, R.: Heat and Water Balance Estimates over the Tibetan Plateau in 1997-1998, Journal of the Meteorological Society of Japan, 83, 577-593, https://doi.org/10.2151/jmsj.83.577, 2005.

Yamanaka, T.: Summary of Studies Using Environmental Isotope Tracers, Bulletin of the TERC, the University of Tsukuba, 13, 45-58, https://doi.org/10.15068/00147045, 2012.

Yamanaka, T., Matsuo, D., Yano, M., Kakubari, J., Iida, S., Wakui, H., Shimizu, R., and Tanaka, T.: Difference in Root System among Co-occurring Plants in a Secondary Pine Forest Undergoing Succession, Bulletin of the TERC, the University of Tsukuba, 6, 39-44, https://doi.org/10.15068/00147120, 2005.

Yasui, Y. and Oikawa, T.: Daily and Seasonal changes of Soil Respiration Rates and Micrometeorological Conditions of a Red Forest Floor in University of Tsukuba, Bulletin of the TERC, the University of Tsukuba, 18, 77-91, 1993.

Yubasaki, S., Tase, N., and Haginoya, S.: Consideration for the Estimation Methods of Evapotranspiration at Terrestrial Environment Research Center, Bulletin of the TERC, the University of Tsukuba, 6, 45-51, https://doi.org/10.15068/00147121, 2005. 